\title{
Glutamina e turnover do carbono da mucosa intestinal de leitões desmamados
}

\section{Fabiana Ribeiro Caldara ${ }^{1}$, Carlos Ducatti ${ }^{2}$, Dirlei Antonio Berto ${ }^{3}$, Juliana Célia Denadai ${ }^{4}$, Rodrigo Garófallo Garcia ${ }^{1}$, Viviane Maria Oliveira dos Santos Ferreira ${ }^{1}$}

\footnotetext{
1 Universidade Federal da Grande Dourados, Faculdade de Ciências Agrárias, Dourados, MS, Brasil.

2 Universidade Estadual Paulista (Unesp), Instituto de Biociências (IB), Centro de Isótopos Estáveis, Botucatu, SP, Brasil.

${ }^{3}$ Universidade Estadual Paulista, Faculdade de Medicina Veterinária e Zootecnia, Departamento de Produção e Exploração Animal, Botucatu, SP, Brasil.

4 Universidade Estadual Paulista, Faculdade de Medicina Veterinária e Zootecnia, Departamento de Nutrição e Melhoramento Animal, Botucatu, SP, Brasil.
}

RESUMO - Um experimento foi conduzido para verificar a influência da glutamina no turnover do carbono na mucosa intestinal de leitões desmamados. Nove matrizes receberam dietas compostas basicamente de plantas do ciclo fotossintético $\mathrm{C}_{4}$ durante toda a gestação $\left(\delta \%{ }^{13} \mathrm{C}=-17,12\right)$ e lactação $\left(\delta \%{ }^{13} \mathrm{C}=-19,26\right)$. Os leitões foram desmamados aos 21 dias de idade e 68 deles foram alimentados com ração composta de plantas do ciclo fotossintético $C_{3}\left(\delta \%{ }^{13} \mathrm{C}=-25,12\right)$. Os leitões foram aleatoriamente distribuídos em duas dietas: uma sem suplementação de glutamina; e outra suplementada com $1 \%$ de glutamina. Aos $0 ; 1 ; 1,5 ; 2 ; 2,5 ; 3 ; 3,5 ; 4 ; 4,5 ; 5 ; 5,5 ; 8 ; 11 ; 15,20 ; 29$ e 46 dias pós-desmame, dois leitões de cada dieta foram abatidos para coleta de amostras da mucosa intestinal, que foram analisadas quanto à composição isotópica de $\delta \%{ }^{13} \mathrm{C}$ e mensurada a velocidade de substituição do carbono no tempo. Os valores da meia-vida do carbono para a mucosa intestinal foram de 6,0 e 3,5 dias para as dietas controle e com glutamina, respectivamente. A glutamina acelerou a velocidade de substituição do carbono na mucosa intestinal, evidenciando sua ação benéfica na recuperação da estrutura do intestino após o desmame.

Palavras-chave: carbono-13, desmame, epitélio intestinal, suínos

\section{Glutamine and carbon turnover of the intestinal mucosa of weaned piglets}

\begin{abstract}
An experiment was carried out to evaluate the influence of glutamine on the carbon turnover in the intestinal mucosa of weaned piglets. Nine matrices received diets predominantly composed by photosintetic cycle $\mathrm{C}_{4}$ plants during the gestation $\left(\delta \%{ }^{13} \mathrm{C}=-17.12\right)$ and lactation $\left(\delta \%{ }^{13} \mathrm{C}=-19.26\right)$. The piglets were weaned at 21 days of age, and 68 animals were fed rations composed by photosintetic cycle $\mathrm{C}_{3}$ plants $\left(\delta \%{ }^{13} \mathrm{C}=-25.12\right)$. The piglets were distributed at random in two treatments: one diet without glutamine supplementation and the other diet supplemented with $1 \%$ of glutamine. On days 0 ; $1 ; 1.5 ; 2 ; 2.5 ; 3 ; 3.5 ; 4 ; 4.5 ; 5 ; 5.5 ; 8 ; 11 ; 15,20 ; 29$ and 46 after weaning, two piglets from each diet were slaughtered for collection of samples of the intestinal mucosa which were analyzed for their isotopic composition in $\delta \%{ }^{13} \mathrm{C}$ and the carbon substitution speed was measured, in terms of the time. The half-life values of the carbon for the intestinal mucosa were 6.0 and 3.5 days, in control and glutamine treatments, respectively. Glutamine accelerated the carbon substitution speed of the intestinal mucous membrane, evidencing its beneficial action in the recovery of the intestine structure after weaning.
\end{abstract}

Key Words: carbon-13, intestinal epithelium, swine, weaning

\section{Introdução}

O período logo após o desmame é crítico dentro do ciclo produtivo de suínos. O leitão desmamado precocemente apresenta o sistema digestório imaturo, com limitada capacidade de digestão e absorção de nutrientes. Após o desmame, ocorrem mudanças no lúmen intestinal, que acarretam alterações na estrutura e função do intestino delgado, principalmente sobre o tamanho dos vilos e a produção de enzimas digestivas (Xu et al., 2000).
Segundo Pluske et al. (1997), a atrofia das vilosidades após a desmama é causada ou por maior taxa de perda celular ou redução na taxa de renovação das células, decorrente da redução da divisão celular nas criptas. Mahan \& Cera (1993) sugeriram que a principal causa da redução do crescimento pós-desmame é resultado da diminuição na absorção de nutrientes.

O uso de glutamina na dieta de leitões tem mostrado resultados positivos na manutenção da estrutura do intestino ao desmame, tendo em vista a ação trófica direta sobre a 
mucosa intestinal, contribuindo para sua renovação ou integridade (Pluske et al., 1996; Wu et al., 1996; Abreu et al., 2010). Wu et al. (1996) e Lopez et al. (1997) observaram que a adição de 1\% de glutamina na dieta de leitões dos 7 aos 28 dias de idade melhorou a integridade da mucosa intestinal, evitando parte dos efeitos deletérios na morfologia intestinal após o desmame.

Muitos avanços tecnológicos têm ocorrido ao longo dos anos nas áreas de ciências biológicas. Nesse contexto, insere-se a técnica dos isótopos estáveis, bastante indicada em situações onde fontes dietéticas isotopicamente distintas estão disponíveis para os animais. As investigações biológicas têm comprovado que a composição isotópica dos tecidos e fluidos de animais depende principalmente da alimentação, da água ingerida e dos gases inalados (Kennedy \& Krouse, 1990). Dietas isotopicamente distintas podem ser usadas para medir taxas de turnover nos tecidos corporais do animal. Após a troca de dieta, a mudança na composição isotópica do tecido depende de quão rápido esses constituintes são assimilados. Tecidos com rápido metabolismo refletem dietas recentes, enquanto aqueles com baixo turnover metabólico representam dietas consumidas há mais tempo (Hobson \& Clark 1992).

Este trabalho foi realizado com o objetivo de avaliar a influência da glutamina sobre o turnover do carbono da mucosa intestinal de leitões desmamados e, consequentemente, sobre seu processo de renovação.

\section{Material e Métodos}

O experimento foi realizado na Unesp, Botucatu, Faculdade de Medicina Veterinária e Zootecnia, setor de suinocultura.

Nove matrizes da raça Large White foram cobertas e passaram a receber dietas compostas predominantemente de plantas do ciclo fotossintético $\mathrm{C}_{4}$ durante toda a gestação e lactação. Esse procedimento foi adotado para que, ao nascerem, os leitões possuíssem em seus tecidos corporais sinais isotópicos semelhantes ao dessas dietas. Foram coletadas amostras de leite de cinco porcas ao longo do período de lactação, para o monitoramento do sinal isotópico de carbono-13.

Os leitões foram desmamados aos 21 dias de idade e 68 animais foram alojados em galpões de creche, distribuídos em gaiolas metálicas suspensas $(1,0 \times 1,75 \mathrm{~m})$ com piso ripado plástico, equipadas com comedouro metálico automático, bebedouro tipo chupeta e campânula de aquecimento.

A partir do desmame, os animais passaram a receber ração composta predominantemente por plantas do ciclo fotossintético $\mathrm{C}_{3}$, possuindo sinal isotópico de ${ }^{13} \mathrm{C}$ distinto das dietas $\mathrm{C}_{4}$ fornecidas às matrizes. $\mathrm{O}$ programa de alimentação foi dividido em duas fases, sendo a primeira de 0 a 14 dias pós-desmame (ração pré-inicial) e a segunda dos 15 aos 46 dias pós-desmame (ração inicial).

Todas as rações utilizadas foram formuladas para apresentarem níveis nutricionais semelhantes àqueles propostos pelo National Research Council (1998) (Tabela 1$)$. Os valores isotópicos $\left(\delta \%{ }^{13} \mathrm{C}\right)$ dos ingredientes usados na ração foram: milho $(-12,45)$, farelo de soja $(-26,56)$, farelo de trigo $(-27,66)$, farinha de trigo $(-26,43)$.

Trinta e quatro leitões foram distribuídos aleatoriamente em duas dietas: uma predominantemente $\mathrm{C}_{3}$, sem suplementação de glutamina (controle); e outra controle, suplementada com $1 \%$ de glutamina (glutamina).

Aos $0 ; 1 ; 1,5 ; 2 ; 2,5 ; 3 ; 3,5 ; 4 ; 4,5 ; 5 ; 5,5 ; 8 ; 11 ; 15,20$; 29 e 46 dias após o desmame, foram tomados aleatoriamente dois leitões por tratamento que após insensibilização, foram abatidos por sangria por meio de incisão da veia jugular. Entende-se como dia zero, o dia do desmame, que tem por

Tabela 1 - Composição percentual, isotópica e nutricional das rações experimentais

\begin{tabular}{|c|c|c|c|c|}
\hline \multirow[b]{2}{*}{ Ingrediente } & \multicolumn{4}{|c|}{ Ração } \\
\hline & Gestação & Lactação & Pré-inicial & Inicial \\
\hline & \multicolumn{4}{|c|}{ Composição percentual } \\
\hline & $\%$ & $\%$ & $\%$ & $\%$ \\
\hline Milho & 64,0 & 54,0 & - & - \\
\hline Farelo de soja & 12,0 & 21,0 & 18,6 & 23,50 \\
\hline Farelo de trigo & 20,0 & 9,0 & - & - \\
\hline Farinha de trigo ${ }^{1}$ & - & - & 41,4 & 60,50 \\
\hline Concentrado/Núcleo & 4,0 & 16,0 & 40,00 & 16,00 \\
\hline \multirow[t]{3}{*}{ Total } & 100,0 & 100,0 & 100,0 & 100,0 \\
\hline & \multicolumn{4}{|c|}{ Composição isotópica ${ }^{2}$} \\
\hline & $\%$ & \%о & $\%$ & $\%$ \\
\hline$\delta \%{ }^{13} \mathrm{C}$ estimado & $-17,12$ & $-18,81$ & $-25,01$ & $-26,05$ \\
\hline \multirow[t]{2}{*}{$\delta \%{ }^{13} \mathrm{C}$ analisado } & $-17,12$ & $-19,26$ & $-24,87$ & $-25,37$ \\
\hline & \multicolumn{4}{|c|}{ Composição nutricional calculada 3} \\
\hline EM, kcal/kg & 2981 & 3200 & 3404 & 3293 \\
\hline $\mathrm{PB}, \%$ & 14,6 & 19,0 & 20,3 & 21,7 \\
\hline Lisina, \% & 0,64 & 0,95 & 1,40 & 1,17 \\
\hline Metionina, \% & 0,23 & 0,30 & 0,37 & 0,35 \\
\hline Treonina, \% & 0,53 & 0,71 & 0,78 & 0,74 \\
\hline Triptofano, \% & 0,16 & 0,22 & 0,24 & 0,26 \\
\hline Cálcio, \% & 1,21 & 1,11 & 0,89 & 0,90 \\
\hline P disponível, \% & 0,40 & 0,42 & 0,46 & 0,44 \\
\hline Lactose, \% & - & - & 8,00 & 5,00 \\
\hline
\end{tabular}

${ }^{1}$ Nas rações pré-inicial e inicial no tratamento com glutamina, este aminoácido foi adicionado (1\%) em substituição a farinha de trigo, sem alterações significativas nos valores nutricionais e isotópicos.

2 Valores isotópicos das matérias-primas utilizadas: milho (-12,45\%o), farelo de soja $(-26,56 \%)$, farelo de trigo $(-27,66 \%)$, farinha de trigo $(-26,43 \%)$, suplemento vitamínico/mineral gestação $(-10,89 \%)$, núcleo lactação $(-25,14 \%)$, núcleo pré-inicial (-22,83\%), núcleo inicial $(-23,85 \%)$.

${ }^{3}$ Valores calculados com base na composição das matérias-primas propostas por Rostagno et al. (2000) e composição de núcleos e concentrados fornecidos pela empresa Maxi Nutrição Animal. 
objetivo expressar a composição isotópica do alimento consumido antes da troca (neste caso, a ração fornecida às matrizes e o leite consumido pelos leitões). Nos dias 1, 2, 3, 4 e 5, os abates foram realizados em dois períodos: manhã (6 h) e tarde (18 h). Nos demais dias o abate foi realizado apenas no período da manhã (6 h).

Imediatamente após o abate os animais foram eviscerados e com o auxílio de pinças o intestino delgado foi seccionado a partir da $5^{\mathrm{a}}$ alça intestinal (jejuno), obtendo-se uma porção de aproximadamente $30 \mathrm{~cm}$ de comprimento. $\mathrm{O}$ segmento amostrado do intestino foi lavado com solução fisiológica, aberto pela borda mesentérica, novamente lavado e foram coletadas amostras de mucosa através de raspagem com lamínula de vidro.

Adicionalmente, foram coletadas amostras de digesta ileal obtidas da porção final do íleo (aproximadamente $30 \mathrm{~cm}$ ), com o objetivo de avaliar a capacidade de adaptação dos leitões ao desmame, refletido pelo consumo de alimento. As amostras foram acondicionadas em frascos ependorf, identificadas e imediatamente congeladas $-18^{\circ} \mathrm{C}$, até a sua preparação para as análises isotópicas.

Para a realização das análises isotópicas da mucosa intestinal e digesta ileal, as amostras foram descongeladas e secas em estufa de ventilação forçada a $60^{\circ} \mathrm{C}$ por um período de 36 horas. Todas as amostras, inclusive matériasprimas erações, foram moídas em moinho criogênico, a- $190^{\circ} \mathrm{C}$, por três minutos, em alta freqüência para obtenção de material homogêneo, com aspecto microscópico.

Para a determinação da composição isotópica das amostras foi utilizado o espectrômetro de massa de razões isotópicas, do Centro de Isótopos Estáveis Ambientais, do Instituto de Biociências da UNESP, Campus de Botucatu. Os resultados foram expressos em notação $\delta \%{ }^{13} \mathrm{C}$, em relação ao padrão internacional Peedee Belemnite (PDB), com erro de análise da ordem de $0,2 \%$ e calculado pela equação:

$$
\delta \%{ }^{13} \mathrm{C}_{(\text {amostra, padrão) }}=\left[\left(\mathrm{R}_{\text {amostra }} / \mathrm{R}_{\text {padrão }}\right)-1\right] \times 10^{3}
$$
em que: $\delta \%{ }^{13} \mathrm{C}=$ enriquecimento da razão ${ }^{13} \mathrm{C} /{ }^{12} \mathrm{C}$ da amostra em relação ao padrão; $\mathrm{R}$ = razão isotópica $\left({ }^{13} \mathrm{C} /{ }^{12} \mathrm{C}\right)$ da amostra e do padrão.

Os dados isotópicos obtidos foram compilados em curva isotópica padrão, com auxílio do programa Origin 6.0 Professional (Microcal Software Original 6.0 Professional, 1999), e para avaliação da velocidade de substituição do carbono das dietas na mucosa intestinal e digesta ileal dos leitões, foi empregada função exponencial de primeira ordem, expressa pela equação, de acordo com Ducatti et al. (2002):

$$
\delta \%{ }^{13} \mathrm{C}(\mathrm{t})=\delta \%{ }^{13} \mathrm{C}(\mathrm{f})+\left[\delta \%{ }^{13} \mathrm{C}(\mathrm{i})-\delta \%{ }^{13} \mathrm{C}(\mathrm{f})\right] \mathrm{e}^{-\mathrm{kt}}
$$
em que: $\delta \%{ }^{13} \mathrm{C}(\mathrm{t})$ = enriquecimento isotópico do tecido em qualquer tempo (t); $\delta \%{ }^{13} \mathrm{C}(\mathrm{f})=$ enriquecimento isotópico do tecido no patamar de equilíbrio, ou condição final; $\delta \%{ }^{13} \mathrm{C}(\mathrm{i})=$ enriquecimento isotópico do tecido, na condição inicial; $\mathrm{k}=$ constante de troca (turnover) em unidades de tempo ${ }^{-1}, \mathrm{t}=$ tempo (em dias) desde a substituição da ração.

A meia-vida do carbono na mucosa intestinal e digesta ileal dos leitões de ambos os tratamentos, em $t=T$, foi calculada pela equação:

$$
\mathrm{T}=\ln 2 / \mathrm{k}
$$

em que: $\mathrm{T}$ = meia-vida (dias); $\mathrm{ln}=$ logaritmo neperiano; $\mathrm{k}$ = constante de turnover $\left(\operatorname{dia}^{-1}\right)$, indicando a "velocidade" no processo de troca dos isótopos estáveis nos tecidos e digesta ileal (Ducatti et al., 2002).

\section{Resultados e Discussão}

As amostras de mucosa intestinal dos leitões no dia zero $\left(\delta^{13} \mathrm{C}=-18,89 \%\right.$ e $-19,21 \%$ para os animais das dietas controle e glutamina, respectivamente), ou seja, antes da troca de alimentação, possuem valores de $\delta \%{ }^{13} \mathrm{C}$ semelhantes ao do leite das matrizes (-18,87\%o) (Figura 1$)$. Esses, por sua vez, se assemelham ao da ração recebida por elas durante o período de lactação (-19,26\%). Esses resultados estão de acordo com a afirmação de Deniro \& Epstein (1978) de que o organismo animal é isotopicamente semelhante ao alimento que consome $\pm 1 \%$ para os isótopos do carbono.

Observando-se os valores do $\delta \%{ }^{13} \mathrm{C}(\mathrm{f})$ em ambas as equações (enriquecimento isotópico do tecido no patamar de equilíbrio, ou condição final), verifica-se que o período experimental de 46 dias foi suficiente para que o $\delta^{13} \mathrm{C}$ tecidual atingisse o patamar de equilíbrio isotópico, uma vez que o valor isotópico de carbono médio das rações fornecidas aos leitões durante o período experimental foi de $-25,19 \%$.

Comparando a velocidade de substituição do carbono na mucosa intestinal entre os tratamentos, verifica-se que, para os animais do grupo controle, o valor de meia-vida encontrado foi quase duas vezes maior em relação àqueles suplementados com glutamina em suas dietas. Essa diferença acentuada evidencia a influência da glutamina sobre a velocidade de troca do carbono no tecido em questão, sugerindo a aceleração no processo de renovação da mucosa intestinal após o desmame.

De acordo com Pierzynowski et al. (2001), a glutamina desempenha papel-chave na manutenção da estrutura e função intestinal sendo indispensável como combustível metabólico para ser oxidada pela mucosa intestinal, além de importante fonte de nitrogênio para os enterócitos. 

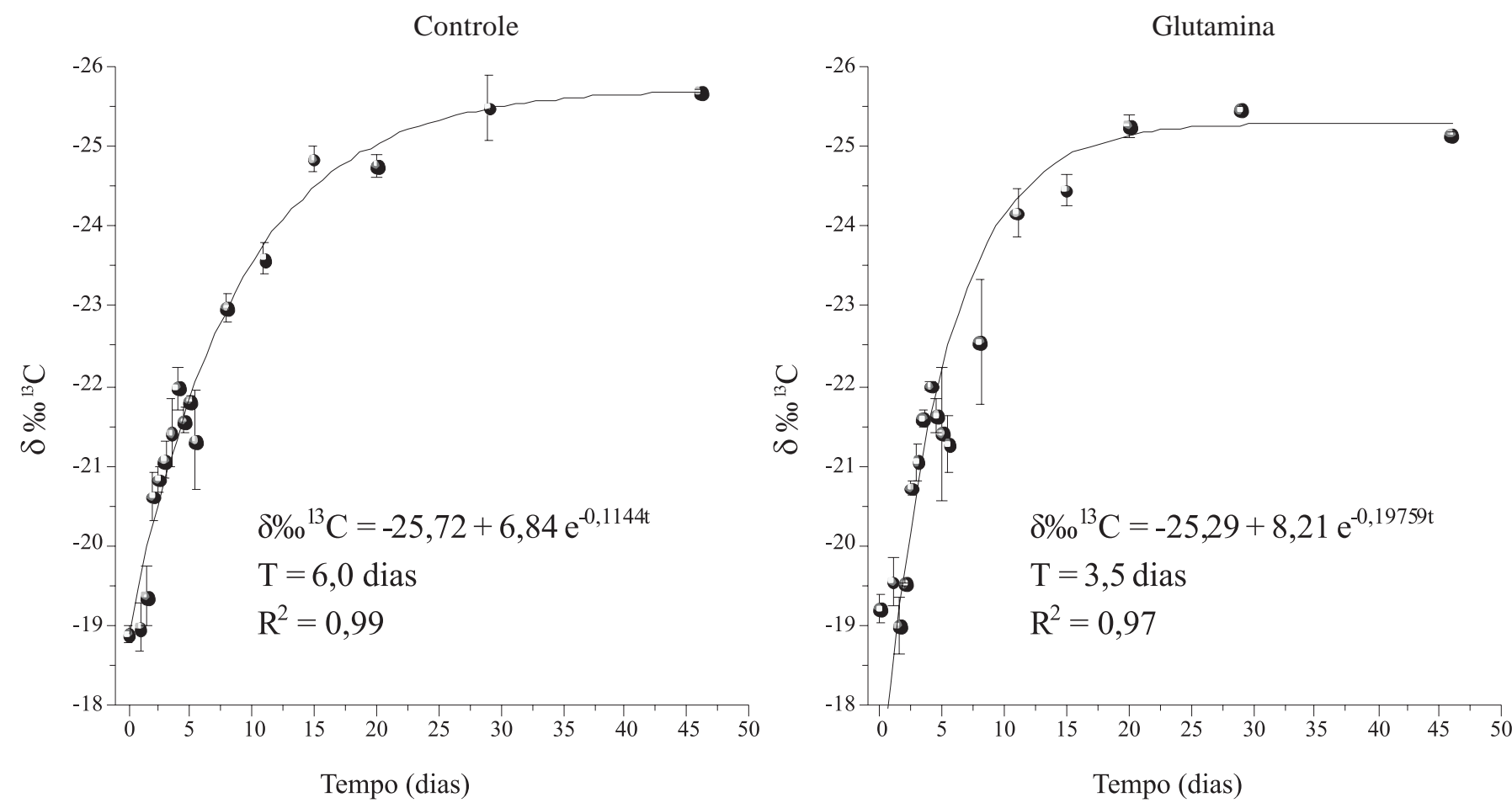

Figura 1 - Composição isotópica ( $\delta \%{ }^{13} \mathrm{C}$, média \pm desvio-padrão) e valor de meia-vida $(\mathrm{T})$ do carbono na mucosa intestinal de leitões alimentados com rações suplementadas ou não com glutamina.

Newsholme \& Carrie (1994) sugeriram que as altas taxas de metabolismo da glutamina nos enterócitos podem ser resultado da necessidade de substrato para a síntese de ácidos nucléicos. Por isso foi argumentado que a glutamina é importante para os enterócitos, tanto como combustível quanto como substrato.

Embora seja considerado um aminoácido não-essencial, estudos recentes demonstram que o estoque de glutamina endógena e a capacidade de síntese podem não ser suficientes para suprir as necessidades do organismo durante longos períodos de estresse, estados hipercatabólicos e hipermetabólicos ou durante jejum prolongado (Boza et al., 2000; Claeyssens et al., 2000). Em função do estresse a que os leitões são submetidos no período do desmame e a redução drástica na ingestão de alimento, é possível que seus estoques de glutamina sejam reduzidos. Isso explicaria a resposta positiva na redução do tempo de renovação da mucosa intestinal dos leitões que receberam ração suplementada com glutamina.

Segundo Pluske et al. (1997), a atrofia das vilosidades após a desmama é causada por aumento na taxa de perda celular ou redução na taxa de renovação celular. Assim, a primeira condição é causada normalmente, pela presença de componentes antigênicos de alimentos e desafios microbianos e a segunda, ocasionada principalmente sob condições de restrição de alimento.
No presente experimento, os animais foram mantidos durante todo o período experimental em instalações com baixos desafios microbianos, e alimentados com rações complexas de baixa inclusão de farelo de soja, principalmente, na primeira fase pós-desmame. Portanto, é mais provável que a redução que normalmente, ocorre no consumo voluntário de alimento nesta fase seja o principal fator a influenciar negativamente a velocidade de renovação das células epiteliais, com conseqüência nas taxas de turnover de carbono tecidual.

De acordo com a literatura, a mucosa intestinal é um tecido com intenso metabolismo e rápida renovação. Porém, os resultados obtidos encontram-se bem acima do esperado quando comparado aos valores sobre o tempo de renovação da mucosa intestinal encontrados em literatura (três a seis dias), visto que os valores encontrados referem-se apenas à meia-vida do carbono tecidual.

Sob condições normais, o intestino delgado perde quantidades significativas de proteína por dia, na forma de células esfoliadas e enzimas secretadas (Ferraris \& Diamond, 1997). De acordo com Goodlad et al. (1988), em mamíferos, a privação de alimento, como ocorre com leitões nos primeiros dias após o desmame, afeta rapidamente a anatomia do intestino delgado pela dramática redução no turnover e taxa de produção de células na cripta para conservar proteínas e energia biossintética. 
Ferraris (2000) afirma que, devido à taxa de migração dos enterócitos e o turnover das células diminuírem em condições de restrição calórica, o tempo de vida das células é maior e, consequentemente, essas células permanecem nos vilos por um longo tempo. Isto explicaria em parte o maior tempo de renovação da mucosa intestinal encontrado no presente trabalho para leitões recém-desmamados comparados a animais adultos mantidos sob condições nutricionais adequadas.

Outro fator importante é a metodologia empregada para avaliar a influência da glutamina sobre o epitélio intestinal. Os valores mencionados neste trabalho referem-se à meiavida do carbono tecidual e se estima que sejam necessárias de 6 a 7 meias-vidas para que ocorra renovação quase total do elemento em questão. Desse modo, independentemente do período considerado (animais recém-desmamados ou adultos), o tempo de renovação do carbono tecidual encontra-se acima das expectativas sobre o tempo de renovação do epitélio intestinal.

De acordo com Rodwell (1990), a renovação proteica do organismo resulta predominantemente da degradação de proteínas musculares a aminoácidos. Em torno de 75\% a 80\% dos aminoácidos liberados da degradação protéica tecidual são reutilizados para síntese de novas proteínas e o restante é metabolizado a nitrogênio, glicose e/ou dióxido de carbono. Segundo Wolfe (1992), do pool de aminoácidos disponível para a síntese proteica em mamíferos, 80\% são derivados da degradação de proteína intracelular.

O tempo de renovação do epitélio intestinal é normalmente avaliado por meio de metodologias, que se utilizam de marcação de células e acompanhamento de seu processo de migração ao longo do eixo cripta-vilo até que sejam extrusadas. Desta forma, conclui-se que havendo a reutilização de carbono tecidual, o tempo de renovação deste elemento no tecido em questão, será superior ao esperado para o tempo de renovação do epitélio intestinal encontrado em literatura.

Houve variação nos valores isotópicos da digesta entre animais da mesma dieta e mesmo dia de coleta nos primeiros dias após o desmame (Figura 2). Essas variações ilustram a diferença individual na adaptação dos animais ao desmame, onde alguns apresentam adaptação mais rápida à ingestão da ração pré-inicial. Um bom exemplo são os animais que foram abatidos no dia 1,5, uma vez que dois deles (um de cada dieta), demonstraram, pelo sinal isotópico de seu conteúdo ileal, não ter ingerido praticamente nada da ração (sinal isotópico próximo ao do leite das porcas), enquanto os demais provavelmente consumiram ração pouco tempo após o desmame.

Esses resultados dão subsídio para o entendimento dos elevados coeficientes de variação para as variáveis de desempenho normalmente observados em experimentos com leitões na fase imediatamente posterior ao desmame.
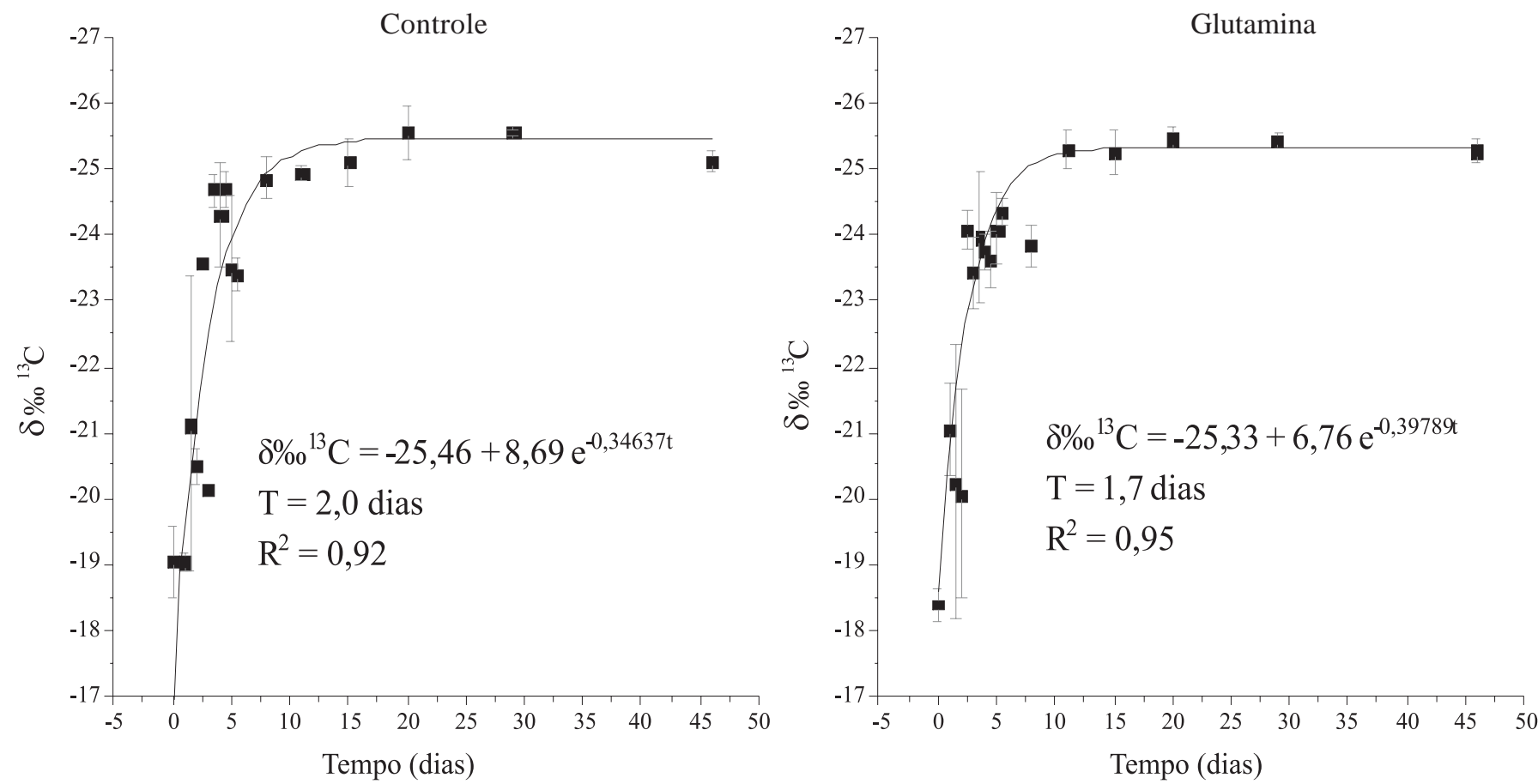

Figura 2 - Composição isotópica ( $\delta \%{ }^{13} \mathrm{C}$, média \pm desvio-padrão) e valor de meia-vida $(\mathrm{T})$ do carbono na digesta ileal de leitões alimentados com rações suplementadas ou não com glutamina. 


\section{Conclusões}

A suplementação de $1 \%$ de glutamina na ração de leitões desmamados acelerou o turnover do carbono da mucosa intestinal, indicando resposta positiva no processo de renovação desse tecido e que a capacidade de adaptação dos leitões ao desmame varia entre indivíduos.

\section{Referências}

ABREU, M.L.T.; DONZELE, J.L.; SARAIVA, A. et al. Glutamina, nucleotídeos e plasma suíno em rações para leitões desmamados. Revista Brasileira de Zootecnia, v.39, n.3, p.520-525, 2010.

BOZA, J.J.; MAIRE, J.C.; BOVETTO et al. Plasma glutamine response to enteral administration of glutamine in human volunteers (free glutamine versus protein-bound glutamine). Nutrition, v.16, p.1037-1042, 2000.

CLAEYSSENS, S.; BOUTELOUP-DEMANGE, C.; GACHON, P. et al. Effect of enteral glutamine on leucine, phenylalanine and glutamine metabolism in hypercortisolemic subjects. American Journal of Physiology, v.278, p.E817-E824, 2000.

DENIRO, M.J.; EPSTEIN, S. Influence of diet on the distribution of carbon isotopes in animals. Geochimica et Cosmochimica Acta, v.42, p.495-506, 1978.

DUCATTI, C.; CARRiJo, A.S.; PEZZATO, A.C. et al. Modelo teórico e experimental da reciclagem do carbono - 13 em tecidos de mamíferos e aves. Scientia Agricola, v.59, p.29-33, 2002.

FERRARIS, R.P.; DIAMOND, J. Regulation of intestinal sugar transport. Physiological Reviews, v.77, p.257-302, 1997.

FERRARIS, R.P. Intestinal transport during fasting and malnutrition. Annual Review of Nutrition, v.20, p.195-219, 2000.

GOODLAD, R.A.; PLUMB, J.A.; WRIGHT, N.A. Epithelial cell proliferation and intestinal absorptive function during starvation and refeeding in the rat. Clinical Science, v.74, p.301-306, 1988.

HOBSON, K.A.; CLARK, R.G. Assessing avian diets using stable isotopes I: turnover of ${ }^{13} \mathrm{C}$ in tissues. The Condor, v.94, p.181-188, 1992.

KENNEDY, B.V.; KROUSE, H.R. Isotope fractionation by plants and animals: implications for nutrition research. Canadian Journal of Physiology and Pharmacology, v.68, p.960-972, 1990.
LOPEZ, L.C.; BORBOLLA, S.; GERMAN, A. Efecto del suero de leche liquido y l-glutamina sobre la morfología de la mucosa intestinal de lechones lactantes y cerdos recientemente destetados. In: REUNIÓN NACIONAL DE INVESTIGACIÓN PECUARIA, 23., 1997, Vera Cruz, Mexico. Proceedings... Vera Cruz: National Meeting on Livestock Research, 1997. p.82.

MAHAN, D.C.; CERA, K.R. Changes in intestinal morphology - a major reason for the growth check following weaning. Pig News Information, v.14, p.373 (Abstract), 1993.

MICROCAL SOFTWARE ORIGIN® ${ }^{\circledR}$ 6.0 Professional Origin data analysis and technical graphics. Northampton, USA: Microcal Software Inc., 1999.

NATIONAL RESEARCH COUNCIL - NRC. Nutrient requirement of swine. 10.ed. Washington: National Academy of Sciences, 1998. 189p.

NEWSHOLME, E.A.; CARRIE, A.L. Quantitative aspects of glucose and glutamine metabolism by intestinal cells. Gut, v.35, p.S13-S17, 1994.

PIERZYNOWSKI, S.G.; VALVERDE, P.J.L.; HOMMEL-HANSEN, T. et al. Glutamine in gut metabolism. In: PIVA A.; BACHLUDSEN, K.E.; LINDBERG, J.E. (Eds). Gut environment of pigs. Nottingham: Nottingham University Press, 2001. p.43-62.

PLUSKE, J.R.; WILLIAMS, I.H.; AHERNE, F.X. Maintence of villous height and crypt depth in piglets by providing continuous nutrition after weaning. Animal Science, v.62, p.131-144, 1996.

PLUSKE, J.R.; HAMPSON, D.J.; WILLIAMS, I.H. Factors influencing the structure and function of the small intestine in the weaned pig: a review. Livestock Production Science, v.51, p.215-236, 1997.

RODWELL, V.W. Catabolismo do nitrogênio dos aminoácidos. In: MURRAY, R.K. (Ed.) Harper: Bioquímica. São Paulo: Atheneu, 1990. p.276-285.

ROStAgnO, H.S.; ALBinO, L.F.T.; DONZELE, J.L. et al. Composição de alimentos e exigências nutricionais de aves e suínos: Tabelas brasileiras. Viçosa, MG: Universidade Federal de Viçosa, 2000. 141p.

WOLFE, R.R. Radioactive and stable isotope tracers in biomedicine: principles and practice of kinetic analysis. New York: Wiley-Liss, 1992. 471p.

WU, G.; MEIER, S.A.; KNABE, D. Dietary glutamine supplementation prevents jejunal atrophy in weaned pigs. Journal of Nutrition, v.126, p.2578-2584, 1996.

XU, R.J.; WANG, F.; ZHANG, S.H. Postnatal adaptation of the gastrointestinal tract in neonatal pigs: a possible role of milkborne growth factors. Livestock Production Science, v.66, p.95-107, 2000 . 